\title{
OPTIMIZATION OF PRODUCTION PROCESS OF PEELED GRAINS OF WHEAT OF DIFFERENT SOLIDITY
}

\author{
Grygory Gospodarenko \\ Department of agrochemistry and soil science \\ Uman National University of Gardening \\ 1 Institutska str., Uman, Ukraine, 20305 \\ hospodarenko@gmail.com \\ Vitaly Lubych \\ Department of technology of grain processing \\ Uman National University of Gardening \\ 1 Institutska str., Uman, Ukraine, 20305 \\ lyubichv@gmail.com \\ Volodimyr Novikov \\ Department of technology of grain processing \\ Uman National University of Gardening \\ 1 Institutska str., Uman, Ukraine, 20305 \\ 1990vovanovikov1990@gmail.com
}

\begin{abstract}
Wheat is a leading agricultural plant with one of most gross grain harvest in the world. It is a valuable raw material for producing the wide assortment of food products. That is why little studied peculiarities of it need specification, and processing technologies - improvement.

The aim of the conducted studies was in specifying of processing regimes of solid and soft wheat grains into peeled ones that allowed to choose rational regimes of water-thermal processing for attaining their maximal output, boiling coefficient and decrease of a preparation duration.

It was proved, that the effect of heat and moisture mostly influences the output of grains and duration of their boiling, despite the solidity. The boiling coefficient depends on the solidity type more.

The optimal mode as to thermal processing at production of peeled grains of soft wheat is is steaming during 10 min with hydration during 10-12 min.

It is rational to steam solid wheat during 10 min with further hydration during $12-13 \mathrm{~min}$ at processing.

Keywords: water-thermal processing; peeled grains; boiling coefficient; solidity of grains.

\section{Introduction}

Wheat is a main grain culture in the world that is a valuable source of vegetable protein for people. Comparing with rice and corn, wheat is a raw material for many food products, especially bakery ones and peeled grains. It is conditioned by the special structure of wheat protein that is formed of $60-80 \%$ of gliadins and glutenins [1].

Almost $55 \%$ of carbohydrates and $60 \%$ of calories, consumed in the world, are originated by wheat grains [2].

Wheat grains are saturated with macro- and microelements and the use of modern agrotechnological elements allows their effective increase [3].

But despite the wide spread and popularity, wheat proteins can cause an allergic reaction in the human organism that stimulates the work of genetic engineering and selection as to leveling the correspondent negative effect $[4,5]$.

Today there is fixed the essential increase of the number of varieties and lines of wheat. They have improved technological properties, increased quality, high biological value. So, despite the centuries-old history of using wheat grains, adaption of new varieties to conditions of modern production is urgent.
\end{abstract}


Under conditions of modern market economy it is prospective to widen the assortment of ready products, especially peeled grains that are very important in the human food ration. It is also effective to decrease energy consumption at processing raw materials, increase of technological efficiency at production enterprises.

\section{Analysis of literary data and stating of problem}

Grain wheat products together with bakery ones are traditional in the food ration. They have a high culinary and food value. At that last time there was fixed the increase of requirements to safety of wheat grains, especially, the content of microtoxins that favorably differs wheat as a food raw material [6]. Their content in products of child nutrition is especially controlled [7].

The growing popularity is inherent to products with the increased content of food fibers of wheat grains. They are mostly located in peripheral parts of a grain. The presence of food fibers in the ration favors the increase of a satiety feeling at the expanse of decelerating a digestion velocity and absorbing microelements [8].

It is proved that grain products with the high content of food fibers are filled with phytochemical substances, including phenol acids, tanning substances, anthocyans, phytosterols, avenanthramides and polycosanols. But correspondent products have a hard effect on the human digestive tract. That is why their use is recommended within compositional mixtures [9].

"Rules of organization and conduction of the technological process at grain plants", valid in Ukraine, provide complete or partial peeling of wheat grains that conditions the low output of grain products (60-63\%). Taking into account the content of endosperm in wheat grains as $80 \%$, their essential part becomes a waste at processing.

It is an innovation to use shortened technological schemes of producing peeled grains with the controlled peeling process. It is proved, that at the index of peeling wheat grains as $10-12 \%$, a grain product with high culinary characteristics may be obtained [10].

Wheat siftings are also a valuable product. Their modification allows to obtain a food supplement that can positively influence the human health and is recommended for subjects with diabetes mellitus type 2 [11].

One of methods of widening the assortment of grain products is the use of grain peeling. Flakes and peeled grains are popular due to the shortened term of preparation and high assimilability. Formation of a flake of wheat peeled grains after a peeling bench and preservation of its form at transporting are attained at the expanse of gelatinization of starch grains of flour endosperm. Starch gelatinization takes place at increased temperatures, attained as a result of hot conditioning (water-thermal processing). Steam production and its transportation to steamers is a complicated, labor-consuming process that essentially increases a prime cost of grain products. But the positive effect of thermal processing on a ready product may be effectively used by the marketing service of a processing enterprise.

It is known, that phytates of ferrum and zinc are contained in wheat grains. They decrease bioavailability of products of grain processing. It was established, that [12], the unessential decrease of phytate (by $11 \%$ ) may be achieved as a result of germination of grains $\left(15{ }^{\circ} \mathrm{C}, 120\right.$ hours). But the use of thermal processing of germinated grains allows to decrease the phytate content by $95 \%$. Thermal processing of wheat grains favors the bioavailability of zinc from 3 to $27 \%$, and ferrum from 5 to $37 \%$.

Water-thermal processing is effectively used for getting arabynoxyl oligosaccharides of wheat siftings [13].

Deoxynivalenol (DON) is the most spread trichothecene in nature that can influence the animal and human health by causing diarrhea, spew, inflammation of the gastrointestinal tract and immune modulation. The partial decrease and transformation of this mitoxen is fixed as a result of water-thermal processing [14].

In Western and Eastern Africa there are used steamers on alternative types of fuel that are in demand. A new steamer is constructed using non-corrosive steel (Inox 304) and set directly on the improved stove, produced of baked bricks. Despite the easiness of construction, these apparatuses have the low duration of water boiling and specific consumption of fuel. The absence of a net of 
pipelines for conducting steam from a steam-generator to a steamer decreases energy consumption for steam transportation [15].

For intensifying the process of water-thermal processing, there is used preliminary hydration of raw materials, and their germination in separate cases. Processing of prepared raw materials in apparatuses with an increased pressure essentially improves the quality of a ready product [16].

Processes that take place in a grain are studied at the molecular level, and the dynamics of water penetration, microstructural changes in water-thermal processing are established [17].

The question of wheat grain solidity remains little-studied. In whole grain solidity is the ability to destructing starch granules of endosperm under the effect of external forces. There are distinguished two types of wheat by a grain solidity parameter: soft and solid. Technologies of producing peeled wheat grains don't contain recommendations that take into account a type of grain solidity.

So, analyzing modern literary sources, one can make the following conclusions. Wheat is one of leading world agricultural plants. The great attention is paid to its selection, study of its quality, biological value and safety. Technologies of wheat processing in flour and peeled grains have the century-old history and improve dynamically. Today technological properties of wheat grains of different solidity remain insufficiently studied, and technologies of their processing in peeled grains need optimization.

The aim of the conducted studied was in specifying of processing regimes of solid and soft wheat grains into peeled ones that allowed to choose rational regimes of water-thermal processing for attaining their maximal output, boiling coefficient and decrease of a preparation duration.

The following tasks were set for attaining this aim:

- to establish the influence of grain solidity on the output and quality of peeled grains;

- to construct a mathematical model of producing peeled grains of soft ones and to establish optimal values of regimes of water-thermal processing;

- to construct a mathematical model of producing peeled grains of solid ones and to establish optimal values of regimes of water-thermal processing;

\section{Materials and methods}

\section{1. Raw material}

The research object was wheat soft grains, planted at an experimental plot of Uman National University of gardening under conditions of Right-bank forest and steppe region of Ukraine. A precursor - occupied stale. Fertilizers: nitrogen ones- $120 \mathrm{~kg} / \mathrm{he}$, phosphorus and potassium $60 \mathrm{~kg} / \mathrm{he}$. Quality parameters: glass-likeness $-95 \pm 4 \%$, nature $720 \pm 16 \mathrm{~g} / \mathrm{l}$, protein content $11,4 \pm 0,6 \%$.

\section{2. Equipment for researches}

Drying of steamed grains was realized in the drying chamber Sadochok (Consumption power - $950 \mathrm{~W}$. Heater type - THE of non-corrosive steel. Speed of heating of an empty chamber to $65{ }^{\circ} \mathrm{C}-20$ minutes. Maximal temperature of a working chamber $-65+/-5^{\circ} \mathrm{C}$.) $($ Fig. 1).

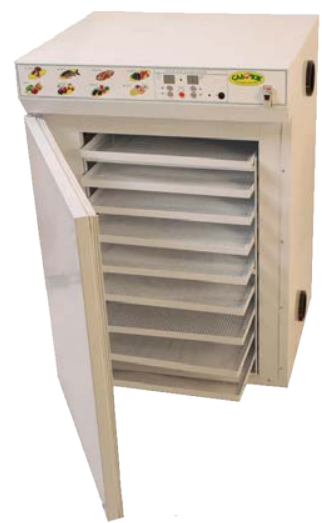

Fig. 1. Drying chamber Sadochok 
Fractionating of peeling products was realized at the laboratory sower LSU-1 (Fig. 2).

For distributing intermediate products, there were used sieves of the first type with round orifices. The sowing scheme is presented on Fig. 5.

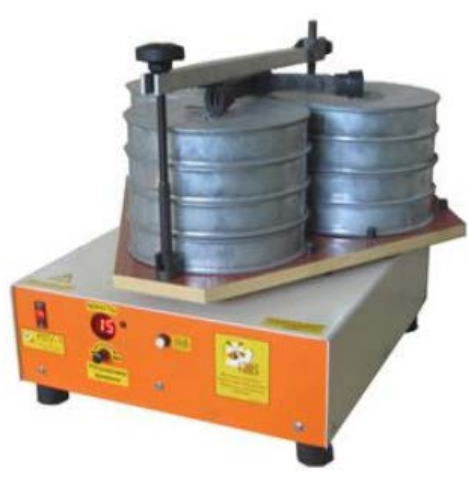

Fig. 2. Laboratory sower LSU-1

For studying the hot conditioning process, there was used the laboratory steamer of periodical action, designed and developed at the department of grain processing and storage technology of Uman national University of gardening, Cherkasy region, Ukraine (Fig. 3).

The steamer SPA-1 includes heating element 8 with the stably fixed body of apparatus 4 . Ball of liquid 7 is placed in the lower part of the body. For preventing losses of steam pressure, collar compaction 5 is provided on regulatory mechanism 6 . Studied sample 3 is placed in the lower part of sieve 2, pressurized by cover 1 .

The working principle of a steamer of periodical action is that the lower part of the working zone of the apparatus is filled with water to the fixed mark of the maximal level. A handle of the steam supply control is set in a horizontal position that conditions the division of the working zone in two parts. Heating continues till the moment, when the working pressure of saturated steam is set in the lower part of the working chamber. After that, the handle of the controlling mechanism of steam supply is set in the maximally vertical position that conditions the instant equating of pressure in both chambers to $0,2 \pm 0,01 \mathrm{MPa}$.

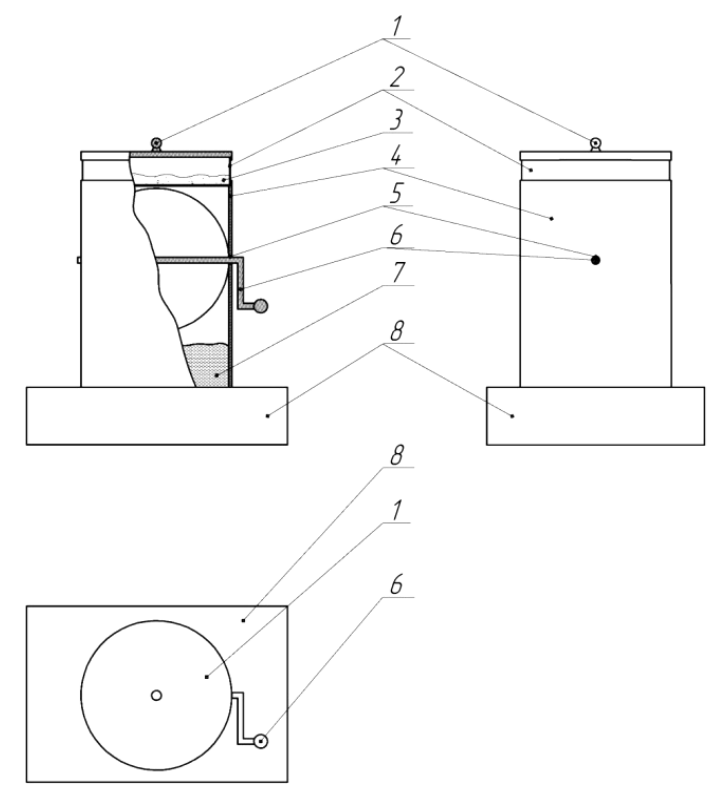

Fig. 3. Laboratory steamer of periodical action SPA-1: 1 - hermetic cover, 2 - sieve, 3 - ball of grain; 4 - steamer body, 5 - collar compaction, 6 - control mechanism of steam supply, 7 - water ball, 8 - heating element 
The cylinder with an experimental sample is set in the working position before supplying steam. Steaming time is controlled by an electronic stopwatch with exactness up to $0,5 \mathrm{~s}$. After steaming the cylinder with the hermetic cover is dismantled.

Grains were peeled at the laboratory peeling bench by Marga (Italy) under conditions of the department of technology of grain processing Uman national university of gardening (Fig. 4). The essence of improvement was in mechanization of the laboratory setting by installing a drive (electric motor and wedge-belt transmission).

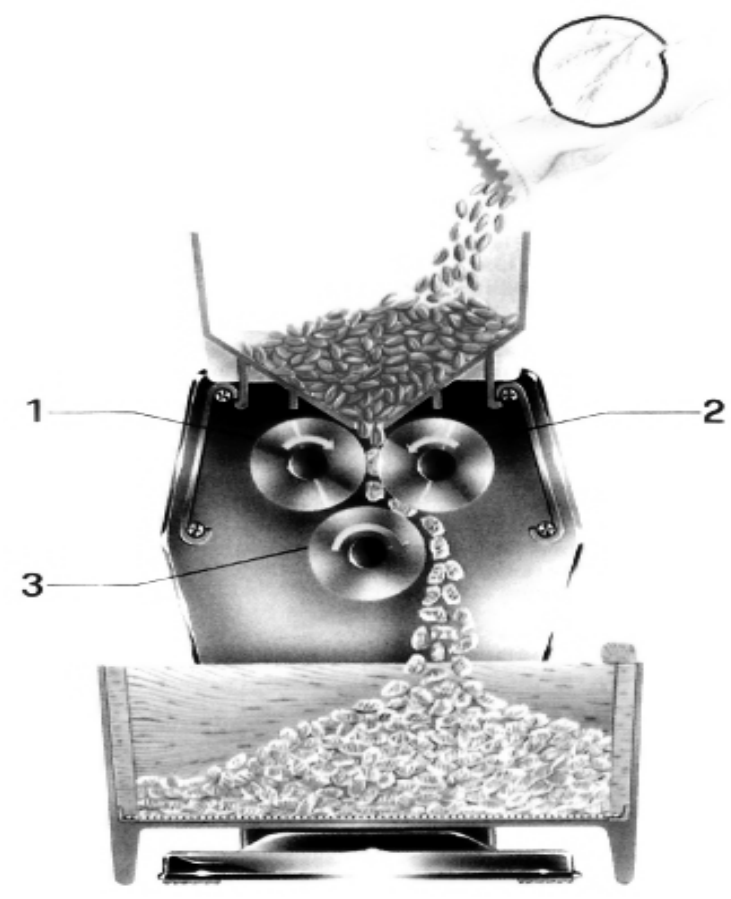

Fig. 4. Laboratory peeling bench by Marga:

1 - low-speed shaft, 2 - high-speed shaft; 3 - shaft for producing flour

The working principle of the peeling machine is in deformation of a raw material by shafts 1 and 2 at orifice $0,5 \mathrm{~mm}$ between them. At producing peeled grains, shaft 3 is set in the inoperative position. Power of the electric motor of the bench is $0,75 \mathrm{~kW}$, rotation frequency of the shaft of the electric motor - $25 \mathrm{~Hz}$, transmission type - wedge-belt one, rotation frequency of the high-speed shaft $-2,5 \mathrm{~Hz}$, productivity of the machine is $0,1 \mathrm{~kg} / \mathrm{min}$, angle of riffles bend -8 , number of riffles for $1 \mathrm{~cm}-10$.

The duration of boiling porridge was determined by the electric stopwatch. The output of peeled grain was determined using laboratory scales with measuring exactness $0,01 \mathrm{~g}$.

\section{3. Statistical processing of experimental data}

The number of analytic repetitions - is four. The results of the analytical repetitions were processed by the methods of describing statistics using programs Microsoft Excel 2010 and STATISTICA 10. The experiment quality was estimated by the value of coefficient of samples variation, formed of the data of the analytic repetitions. The experiment was considered as reliable at unessential variation of the data of the analytical repetitions. Dependencies between factors were found by the method of dispersion and regression analysis. The choice of optimal processing methods was realized by interpolation of samples of experimental data, constructing a desirability function.

The advantage of using desirable diagrams is a possibility of the complex analysis with deducing reliable tendencies and recommendations. The essence of such analysis is in comparison 
of all results of statistical processing of regularities between factors and criteria of improvement, construction of a complex function and search for its experimental values.

\section{4. Program of researches and their methodology}

At the research there was established the influence of main production parameters of peeled grains (steaming duration, hydration duration) on the output of peeled grains, their boiling coefficient and boiling duration. Steps and levels of varying were identical for solid and soft types of grain (Table 1). The technological scheme of getting peeled grains under laboratory conditions is presented on Fig. $\mathbf{5}$.

Grains were peeled before steaming. A peeling index of experimental samples was stable as $10 \pm 0,5 \%$, that conditioned peeled grains of the satisfactory culinary quality.

Porridge was boiled in measuring glass cylinders, placed in the water bath. The boiling coefficient $\left(\mathrm{C}_{b}\right)$ was determined by formula:

$$
\mathrm{C}_{\mathrm{b}}=\frac{\mathrm{V}_{1}}{\mathrm{~V}}
$$

where $\mathrm{V}_{1}$ - porridge volume, $\mathrm{cm}^{3} ; \mathrm{V}$ - peeled grain volume before boiling, $\mathrm{cm}^{3}$.

The boiling duration was determined by the organoleptic estimation of porridge at its preparation. Estimation intervals were chosen individually for each sample for fix a readiness moment maximally exactly. The first estimation was realized after $5 \mathrm{~min}$ of preparing porridge.

Energy consumption was determined by measuring real consumption of electric power of the steamer of periodical action.

Table 1

Steps and levels of varying

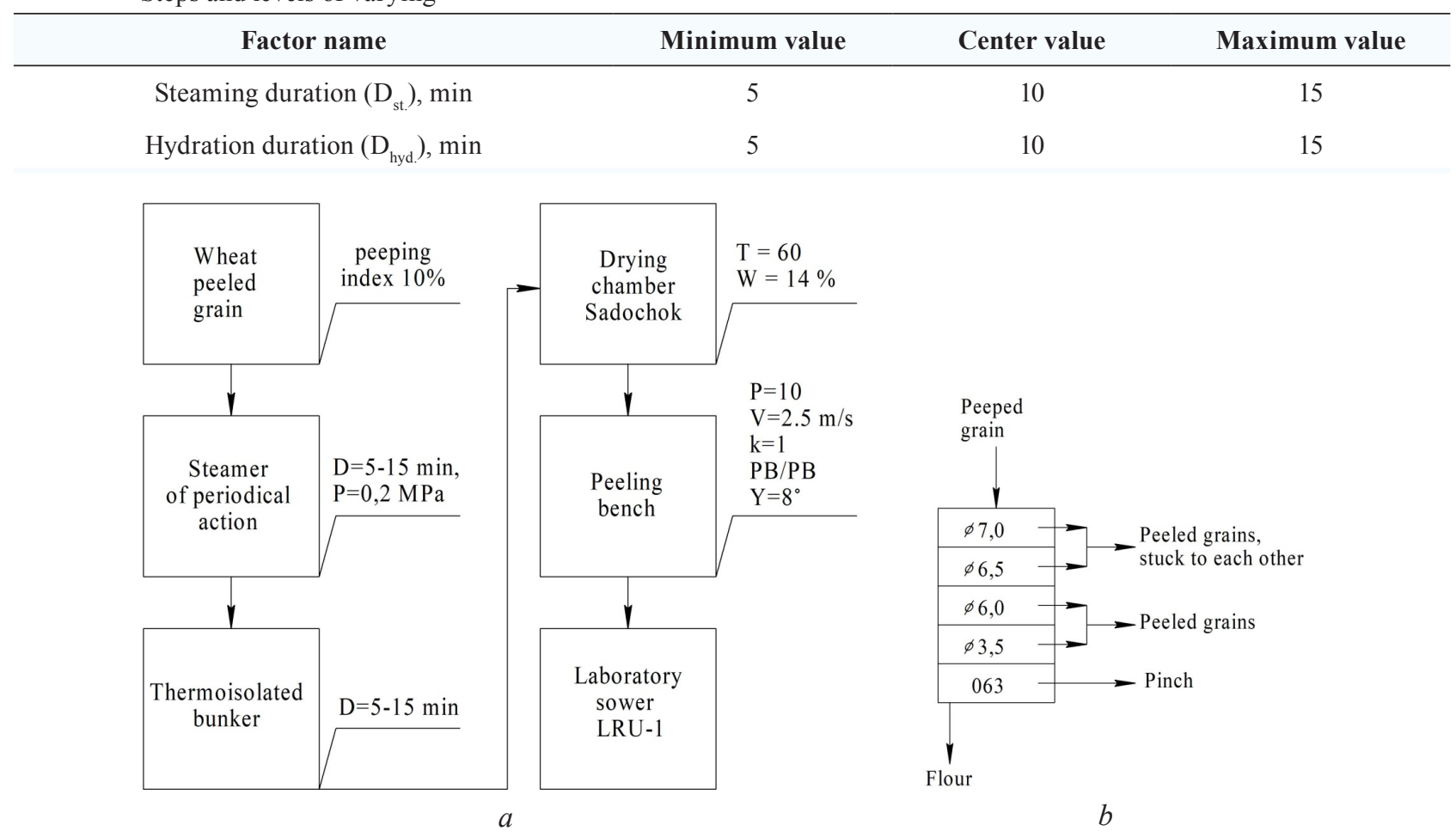

Fig. 5. Conditions of conducted researches: $a$-scheme of laboratory production of peeled grains; $b$ - scheme of laboratory sower LSU-1

\section{Results and discussion}

\section{1. Influence of solidity on the output and quality of peeled grains}

It was established, that the output of peeled grain increases with the growth of steaming and hydration duration despite the solidity of raw materials (Table 2). So, we can state about such 
positive influence of hydration and thermal processing on grains of different solidity. But the more output was inherent to samples, produced of soft grains. It is explained by the higher speed of gelatinization of starch granules of soft grains that as a result decreases the amount of obtained flour. Steaming of grains more than 15 minutes was not effective, because the essential number of stuck grains was wasted. Variation of samples of the output of peeled grains, obtained at different processing regimes, was unessential (for soft grain type $-2,98$; solid type $-2,90$ ).

There was fixed the essential decrease of boiling duration as a result of increasing steaming and hydration duration despite the solidity of raw materials (Coef.Var. $=12,80 ; 10,90)$.

The boiling coefficient of peeled grains, analogously to their output, varied unessentially depending on processing parameters, but was higher in samples of the solid grain type.

So, the influence of a raw material type and parameters of its processing on the output and quality of a product is obvious. But it is rather difficult to establish the reliable connection between these factors by the methods of describing, so it needs further mathematical processing.

Table 2

Output and quality of peeled grains depending on raw material types and parameters of their processing

\begin{tabular}{|c|c|c|c|c|c|}
\hline Grain type & $\mathbf{D}_{\text {st. }}, \min$ & $\mathbf{D}_{\text {hyd. }}, \min$ & Peeled grain output, \% & Boiling duration, min & Boiling coefficient \\
\hline \multirow{9}{*}{ Soft grains } & 5 & 5 & $90,6 \pm 0,9$ & $20,0 \pm 0,2$ & $7,7 \pm 0,2$ \\
\hline & 5 & 10 & $96,9 \pm 1,5$ & $19,0 \pm 0,2$ & $7,7 \pm 0,2$ \\
\hline & 5 & 15 & $95,6 \pm 1,1$ & $19,0 \pm 0,3$ & $7,8 \pm 0,2$ \\
\hline & 10 & 5 & $92,5 \pm 1,0$ & $18,0 \pm 0,2$ & $7,8 \pm 0,2$ \\
\hline & 10 & 10 & $97,8 \pm 1,1$ & $17,0 \pm 0,2$ & $7,9 \pm 0,2$ \\
\hline & 10 & 15 & $96,1 \pm 1,2$ & $16,0 \pm 0,2$ & $8,0 \pm 0,2$ \\
\hline & 15 & 5 & $98,2 \pm 0,9$ & $15,0 \pm 0,3$ & $7,9 \pm 0,2$ \\
\hline & 15 & 10 & $98,5 \pm 0,9$ & $14,0 \pm 0,2$ & $8,0 \pm 0,2$ \\
\hline & 15 & 15 & $97,3 \pm 0,7$ & $14,0 \pm 0,2$ & $8,1 \pm 0,2$ \\
\hline \multirow{19}{*}{ Solid grains } & Mean* & & 95,9 & 16,9 & 7,8 \\
\hline & Median* & & 96,7 & 17,1 & 7,9 \\
\hline & Minimum* & & 89,1 & 13,7 & 7,4 \\
\hline & Maximum* & & 99,2 & 20,2 & 8,3 \\
\hline & Coef.Var.* & & 2,98 & 12,80 & 2,90 \\
\hline & 5 & 5 & $88,4 \pm 1,1$ & $20,0 \pm 0,4$ & $7,9 \pm 0,2$ \\
\hline & 5 & 10 & $94,7 \pm 0,9$ & $20,0 \pm 0,3$ & $7,9 \pm 0,2$ \\
\hline & 5 & 15 & $93,8 \pm 1,4$ & $18,9 \pm 0,5$ & $8,0 \pm 0,2$ \\
\hline & 10 & 5 & $90,8 \pm 0,8$ & $18,0 \pm 0,3$ & $8,1 \pm 0,2$ \\
\hline & 10 & 10 & $95,6 \pm 1,2$ & $16,9 \pm 0,3$ & $8,1 \pm 0,2$ \\
\hline & 10 & 15 & $94,0 \pm 1,4$ & $16,1 \pm 0,3$ & $8,2 \pm 0,2$ \\
\hline & 15 & 5 & $94,5 \pm 1,1$ & $16,1 \pm 0,2$ & $8,1 \pm 0,2$ \\
\hline & 15 & 10 & $96,6 \pm 1,1$ & $15,1 \pm 0,2$ & $8,2 \pm 0,2$ \\
\hline & 15 & 15 & $95,6 \pm 0,7$ & $15,0 \pm 0,1$ & $8,2 \pm 0,2$ \\
\hline & Mean* & & 93,7 & 17,3 & 8,0 \\
\hline & Median* & & 94,6 & 17,0 & 8,1 \\
\hline & Minimum* & & 86,3 & 14,8 & 7,5 \\
\hline & Maximum* & & 97,5 & 20,2 & 8,4 \\
\hline & Coef.Var.* & & 2,90 & 10,90 & 2,80 \\
\hline
\end{tabular}

Note: The results of describing statistics are based on all values of analytical repetitions 
It can be stated with the high reliability that the output of peeled grain and duration of its boiling differed in samples of different grain solidity (Fig. 6). But the null hypothesis was confirmed for the boiling duration index $(p=0,40)$.
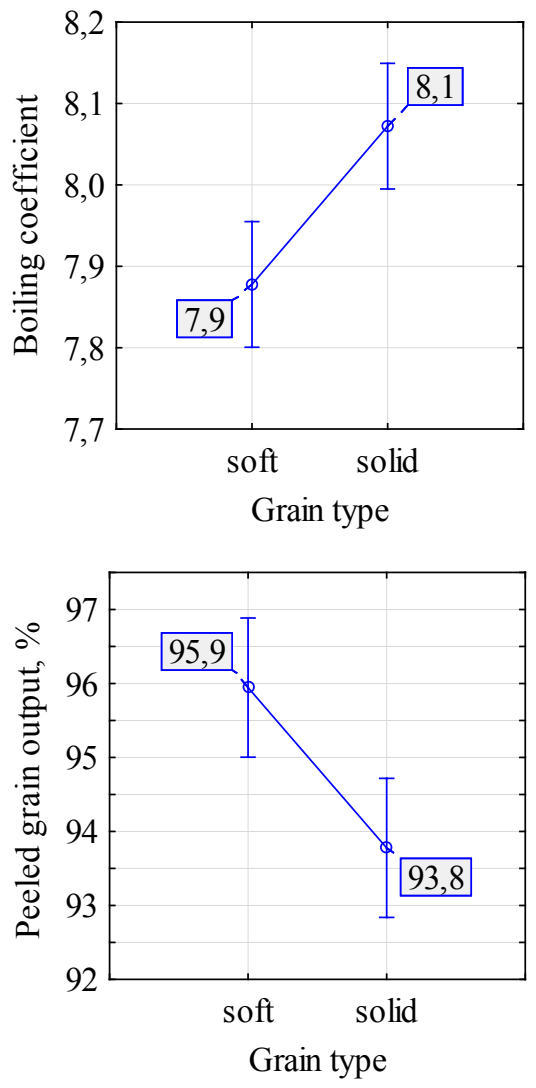

Fig. 6. Peeled grain output and its boiling coefficient depending on grain solidity

At processing wheat of the soft grain type, the output of peeled grain by $2,1 \%$ more can be obtained, but its boiling coefficient is in average by 0,2 un. less.

So, taking into account the reliable influence of the solidity type on parameters of peeled grain production, it is expedient to use this sign at the marketing activity of enterprises. Technical-economic indices of flakes production at processing soft grain type are higher at the expanse of the increased output of a product. It favors the decrease of prime cost of production and obtaining products, available for needy population layers. More consumption at processing solid grain type is compensated by higher organoleptic characteristics.

\section{2. Optimization of processing soft grain type in peeled grains}

The peeled grain output depending on boiling and hydration duration can be most exactly described mathematically using the second kind function $\left(\mathrm{R}^{2}=0,74\right)$ :

$$
\begin{aligned}
& \mathrm{W}=77,28889+0,38 \mathrm{D}_{\mathrm{st}}+0,02867 \mathrm{D}_{\mathrm{st}}{ }^{2}+ \\
& 2,99333 \mathrm{D}_{\text {hyd }}-0,10733 \mathrm{D}_{\text {hyd }}{ }^{2}-0,059 \mathrm{D}_{\mathrm{st}} \mathrm{D}_{\text {hyd }},
\end{aligned}
$$

where $\mathrm{W}$ - peeled grain output, \%; $\mathrm{D}_{\text {st }}$ - steaming duration, min.; $\mathrm{D}_{\text {hyd. }}$ - hydration duration, min.

Analyzing the cogency of regression, it can be stated, that more influence on the output of peeled grains was conditioned by the steaming duration (Fig. 7).

The linear dependence is set between the porridge boiling duration, steaming and hydration duration $\left(\mathrm{R}^{2}=0,96\right)$ : 


$$
\mathrm{D}_{\text {boiling }}=23,24167-0,5 \mathrm{D}_{\text {st }}-0,133333 \mathrm{D}_{\text {hyd }} \text {. }
$$

The influence of steaming duration on boiling duration was essentially more comparing with the influence of hydration duration (Fig. 8).

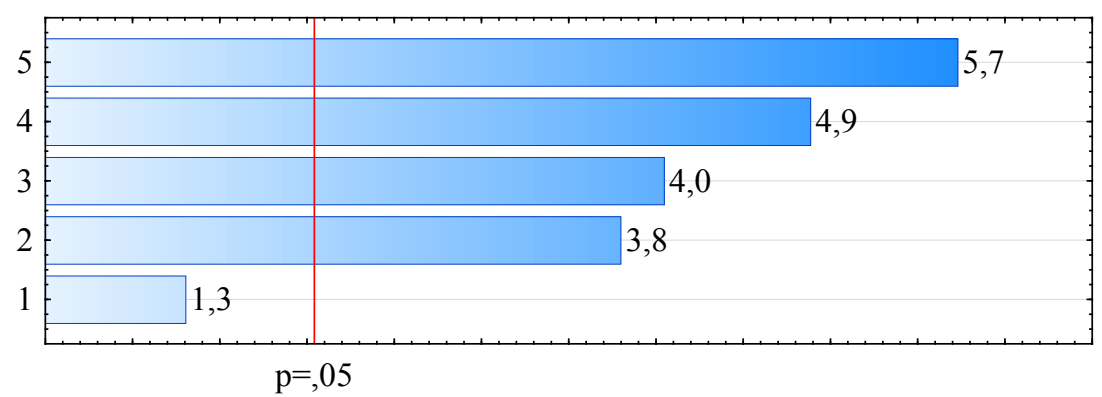

Fig. 7. Pareto diagram of the standardized effect of regression coefficients on the index of soft wheat peeled grain output (absolute value):

$$
1-\mathrm{D}_{\text {st }}^{2} ; 2-\mathrm{D}_{\text {st }} \mathrm{D}_{\text {hyd. }} ; 3-\mathrm{D}_{\text {hyd }} ; 4-\mathrm{D}_{\text {hydr }}{ }^{2} ; 5-\mathrm{D}_{\text {st }}
$$

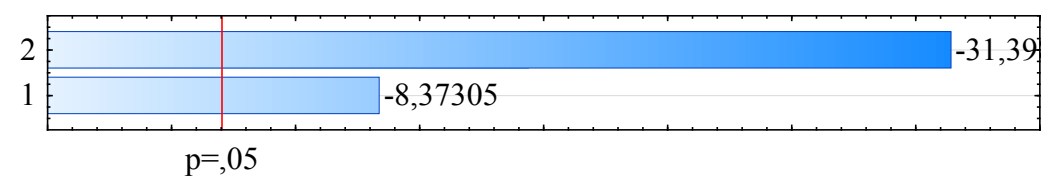

Fig. 8. Pareto diagram of the standardized effect of regression coefficients on the index of soft wheat peeled grain boiling duration (absolute value): $\mathrm{D} 1-\mathrm{D}_{\mathrm{st}} ; 2-\mathrm{D}_{\text {hyd }}$

It is impossible to describe mathematically the influence of peeled grain production parameters on the boiling coefficient, because the reliable level of regression coefficients was low $(p=0,49-0,91)$. It testifies to the presence of the reliable connection between parameters of water-thermal processing of soft type grains and correspondent index. Taking into account that boiling coefficient of soft and solid grain types reliably differed, one can make an assumption about the more important influence of raw materials' characteristics on the correspondent index and absence of its change under production conditions.

The choice of optimal parameters of processing soft type wheat grain was realized taking into account the peeled grain output, boiling duration and energy consumption for the steaming process (Fig. 9).

In whole the increase of steaming duration raised the peeled grain output and decreased its boiling duration, but energy consumption for its production grew in direct proportion. The excessive hydration duration worsened the peeled grain output, whereas hydration during 10-12 min increased it.

The most abrupt decrease of porridge boiling duration was fixed as a result of hydration duration from 5 to $10 \mathrm{~min}$. The further increase of steaming duration decreased the boiling duration unessentially.

At constructing the desirability function, the product output, least duration of its boiling and energy consumption were in priority. For attaining the set criteria, there were chosen regimes, considered as optimal (steaming duration $10 \mathrm{~min}$, hydration duration 10-12 min). At using the recommended regimes at processing soft type wheat grains, there can be gotten the peeled grain output $97,2 \%$ with boiling duration 16,5 min. Although energy consumption for peeled grains production was calculated at the laboratory production, it is impossible to compare their values with industrial conditions, but the established tendency of their change will be valid. 


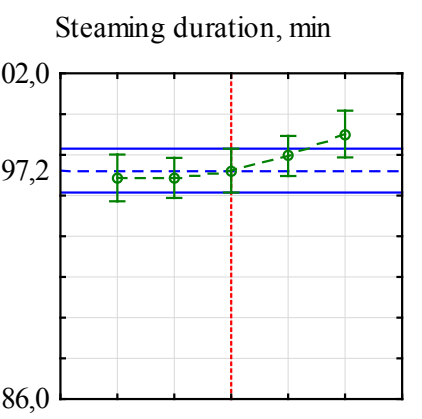

Hydration duration, min

Desirable
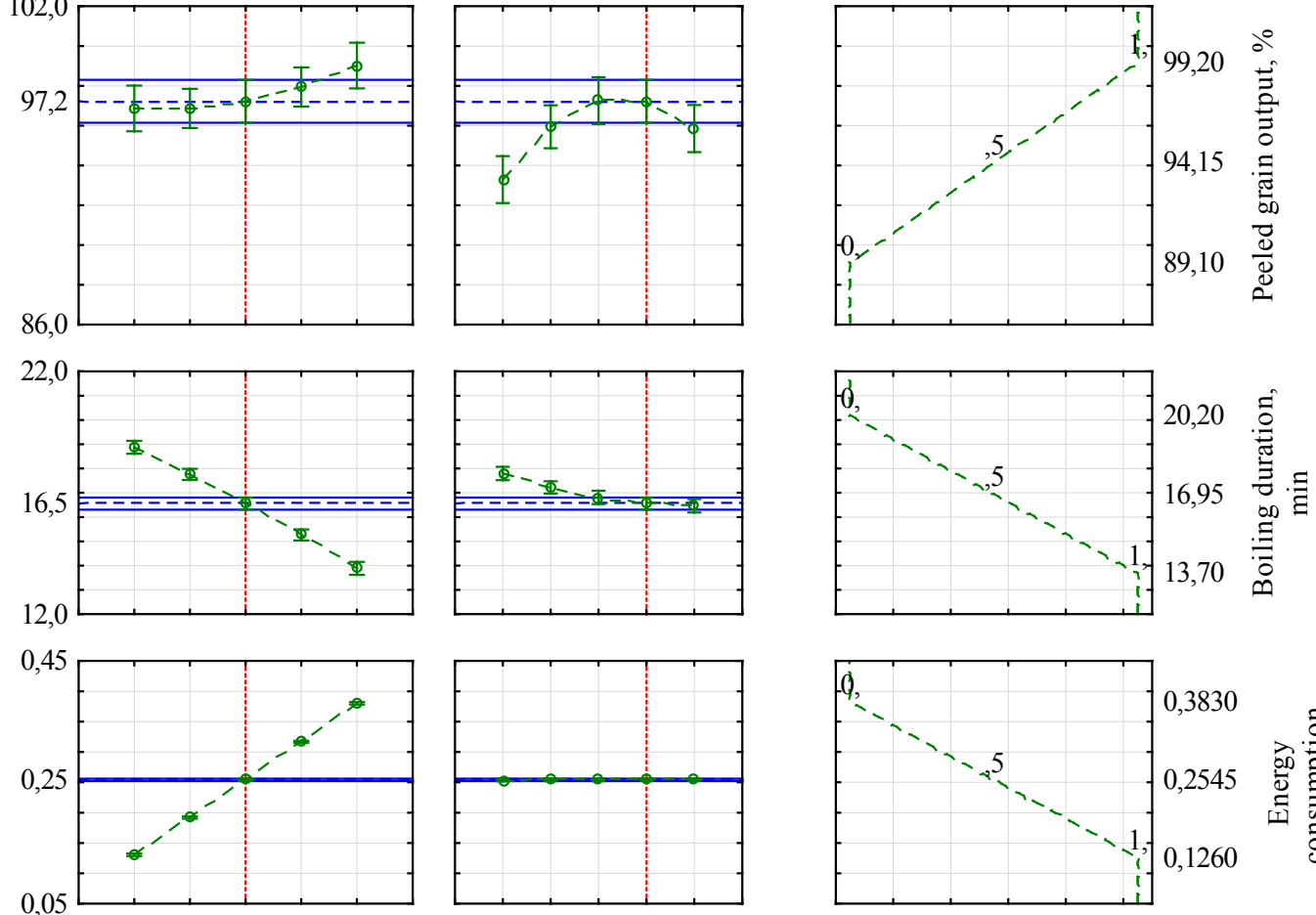

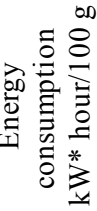
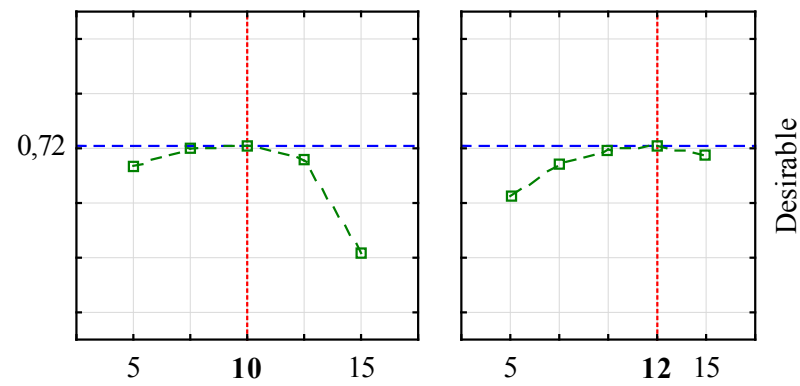

Fig. 9. Profiles of prognosticated values and desirability at processing soft wheat type in peeled grains

\section{3. Optimization of processing solid type grains in peeled grains}

The influence of parameters of water-thermal processing on the peeled grain output, its boiling duration and boiling coefficient was similar to the soft one. It can be expressed rather exactly $\left(\mathrm{R}^{2}=0,76-0,93\right)$ by equation of the second kind:

$$
\begin{aligned}
& \mathrm{W}=75,25556+0,38333 \mathrm{D}_{\text {st }}+0,01867 \mathrm{D}_{\text {st }}{ }^{2}+ \\
& 2,98 \mathrm{D}_{\text {hyd }}-0,11133 \mathrm{D}_{\text {hyd }}{ }^{2}-0,043 \mathrm{D}_{\text {st }} \mathrm{D}_{\text {hyd }} ; \\
& \mathrm{T}_{\text {boil }}=22,88056-0,42083 \mathrm{~T}_{\text {st }}-0,13583 \mathrm{~T}_{\text {hyd }} .
\end{aligned}
$$

The influence of steaming and hydration duration on the grain output was equivalent, but boiling duration was most influenced by the steaming duration (Fig. 10, 11).

The graphic image of functions 3-4 testify that the common zone of optimum of the correspondent functions is in points, similar to the optimum zone of analogous dependences, obtained at processing soft wheat grain (Fig. 12). At processing solid grain type wheato it is rational to steam it during $10 \mathrm{~min}$ with the further hydration during 12-13 $\mathrm{min}$. 




Fig. 10. Pareto diagram of the standardized effect of regression coefficients on the index of solid wheat peeled grain output (absolute value): $1-\mathrm{D}_{\text {st }}{ }^{2} ; 2-\mathrm{D}_{\text {st }} \mathrm{D}_{\text {hyd. }} ; 3-\mathrm{D}_{\text {hyd }} ; 4-\mathrm{D}_{\text {hyd }}{ }^{2} ; 5-\mathrm{T}_{\text {st }}$

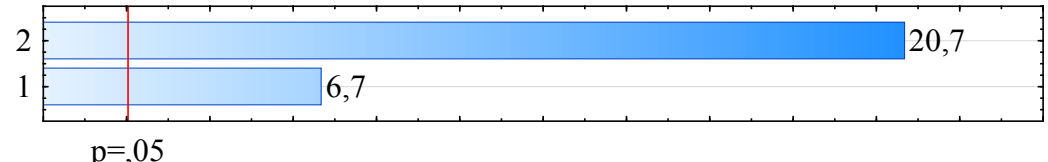

Fig. 11. Pareto diagram of the standardized effect of regression coefficients on the index of solid wheat peeled grain boiling duration (absolute value): $1-\mathrm{D}_{\mathrm{st}} ; 2-\mathrm{D}_{\text {hyd }}$


Fig. 12. Influence of parameters of water-thermal processing on the output and boiling duration peeled grain of solid type wheat

As a result of using the offered regimes the peeled grain output of solid type wheat was $95,4 \%$, and its boiling duration was $16,5 \mathrm{~min}$.

\section{Conclusions}

The reliable connection between the solidity type of wheat grain and important parameters of peeled grain production (output, boiling coefficient), established as a result of the studies, elucidates new aspects in peeled grains production. The obtained research results can be used for widening the assortment of peeled grain products of traditional wheat at the expanse of using grains of different solidity. The lower output of solid wheat peeled grains can be compensated by their higher cost, whereas soft wheat types are suitable for manufacturing cheaper products. In whole the research results, cited in the article, prove the importance of establishment and further study of the influence of grain solidity on qualitative and quantitative indices of peeled grain production. The article presents real energy consumption for hot conditioning, whereas energy consumption at peeling grain of different solidity type remain unknown that conditions the expedience of further studies.

The output of soft type peeled grains $(95,9 \%)$ was more, comparing with the output of solid type peeled grains $(93,8 \%)$. Wheat types reliably differed by the boiling coefficient, whereas the boiling duration for soft and solid wheat types was similar. 
The optimal regime of water-thermal processing at production peeled grains of the soft type is steaming during $10 \mathrm{~min}$ with hydration for $10-12 \mathrm{~min}$.

At processing solid type wheat it is rational to steam it during $10 \mathrm{~min}$ with further hydration for $12-13 \mathrm{~min}$.

\section{References}

[1] Zheng, T., Qi, P.-F., Cao, Y.-L., Han, Y.-N., Ma, H.-L., Guo, Z.-R. et. al. (2018). Mechanisms of wheat (Triticum aestivum) grain storage proteins in response to nitrogen application and its impacts on processing quality. Scientific Reports, 8 (1). doi: http://doi.org/10.1038/s41598-018-30451-4

[2] Nedelkou, I.-P., Maurer, A., Schubert, A., Léon, J., Pillen, K. (2017). Exotic QTL improve grain quality in the tri-parental wheat population SW84. PLOS ONE, 12 (7), e0179851. doi: http://doi.org/10.1371/ journal.pone.0179851

[3] Popko, M., Michalak, I., Wilk, R., Gramza, M., Chojnacka, K., Górecki, H. (2018). Effect of the New Plant Growth Biostimulants Based on Amino Acids on Yield and Grain Quality of Winter Wheat. Molecules, 23 (2), 470. doi: http://doi.org/10.3390/molecules23020470

[4] Wang, H., Zhang, H., Li, B., Yu, Z., Li, G., Zhang, J., Yang, Z. (2018). Molecular Cytogenetic Characterization of New Wheat - Dasypyrum breviaristatum Introgression Lines for Improving Grain Quality of Wheat. Frontiers in Plant Science, 9. doi: http://doi.org/10.3389/fpls.2018.00365

[5] Reig-Otero, Y., Mañes, J., Manyes, L. (2018). Amylase-Trypsin Inhibitors in Wheat and Other Cereals as Potential Activators of the Effects of Nonceliac Gluten Sensitivity. Journal of Medicinal Food, 21 (3), 207-214. doi: http://doi.org/10.1089/jmf.2017.0018

[6] Levasseur-Garcia, C. (2018). Updated Overview of Infrared Spectroscopy Methods for Detecting Mycotoxins on Cereals (Corn, Wheat, and Barley). Toxins, 10 (1), 38. doi: http://doi.org/10.3390/toxins10010038

[7] Ortiz, J., Jacxsens, L., Astudillo, G., Ballesteros, A., Donoso, S., Huybregts, L., De Meulenaer, B. (2018). Multiple mycotoxin exposure of infants and young children via breastfeeding and complementary/weaning foods consumption in Ecuadorian highlands. Food and Chemical Toxicology, 118, 541-548. doi: http://doi.org/10.1016/j.fct.2018.06.008

[8] Ingerslev, A. K., Mutt, S. J., Laerke, H. N., Hedemann, M. S., Theil, P. K., Nielsen, K. L. et. al. (2017). Postprandial PYY increase by resistant starch supplementation is independent of net portal appearance of short-chain fatty acids in pigs. PLOS ONE, 12 (10), e0185927. doi: http://doi.org/10.1371/journal.pone.0185927

[9] Kaur, K. D., Jha, A., Sabikhi, L., Singh, A. K. (2012). Significance of coarse cereals in health and nutrition: a review. Journal of Food Science and Technology, 51 (8), 1429-1441. doi: http://doi.org/10.1007/ s13197-011-0612-9

[10] Hospodarenko, G., Lubich, V., Novikov, V., Polyanetska, I., Voziyan, V. (2017). The impact the type of the wheats on the technical indicators of production cereals and culinary evaluation of the finished product. Bulletin of Uman National University of Horticulture, 1, 38-43.

[11] Lioger, D., Fardet, A., Foassert, P., Davicco, M.-J., Mardon, J., Gaillard-Martinie, B., Remesy, C. (2009). Influence of Sourdough Prefermentation, of Steam Cooking Suppression and of Decreased Sucrose Content during Wheat Flakes Processing on the Plasma Glucose and Insulin Responses and Satiety of Healthy Subjects. Journal of the American College of Nutrition, 28 (1), 30-36. doi: http://doi.org/10.1080/07315724.2009.10719758

[12] Lemmens, E., De Brier, N., Spiers, K. M., Ryan, C., Garrevoet, J., Falkenberg, G. et. al. (2018). The impact of steeping, germination and hydrothermal processing of wheat ( Triticum aestivum L.) grains on phytate hydrolysis and the distribution, speciation and bio-accessibility of iron and zinc elements. Food Chemistry, 264, 367-376. doi: http://doi.org/10.1016/j.foodchem.2018.04.125

[13] Rose, D. J., Inglett, G. E. (2010). Two-Stage Hydrothermal Processing of Wheat (Triticum aestivum) Bran for the Production of Feruloylated Arabinoxylooligosaccharides. Journal of Agricultural and Food Chemistry, 58 (10), 6427-6432. doi: http://doi.org/10.1021/jf100058v

[14] Wu, Q., Kuca, K., Humpf, H.-U., Klimova, B., Cramer, B. (2016). Fate of deoxynivalenol and deoxynivalenol-3-glucoside during cereal-based thermal food processing: a review study. Mycotoxin Research, 33 (1), 79-91. doi: http://doi.org/10.1007/s12550-016-0263-9

[15] Ndindeng, S. A., Manful, J., Futakuchi, K., Mapiemfu-Lamare, D., Akoa-Etoa, J. M., Tang, E. N. et. al. (2015). Upgrading the quality of Africa's rice: a novel artisanal parboiling technology for rice processors in sub-Saharan Africa. Food Sci Nutr, 3 (6), 557-568. doi: http://doi.org/10.1002/fsn3.242

[16] Ndagire, C. T., Muyonga, J. H., Manju, R., Nakimbugwe, D. (2015). Optimized formulation and processing protocol for a supplementary bean-based composite flour. Food Science \& Nutrition, 3 (6), 527-538. doi: http://doi.org/10.1002/fsn3.244

[17] Li, T., Tu, C., Rui, X., Gao, Y., Li, W., Wang, K. et. al. (2015). Study of Water Dynamics in the Soaking, Steaming, and Solid-State Fermentation of Glutinous Rice by LF-NMR: A Novel Monitoring Approach. Journal of Agricultural and Food Chemistry, 63 (12), 3261-3270. doi: http://doi.org/10.1021/acs.jafc.5b00769 